\title{
Innovative Practice
}

\section{Putting Undergraduate Admissions into Context: A Case Study}

\author{
David G. Allison, University of Manchester \\ Email: david.allison@manchester.ac.uk
}

\begin{abstract}
In 2007/08 the School of Pharmacy at the University of Manchester participated in a pilot study run by central admissions looking at the use of contextual data to widen access to higher education. In that study, $27 \%$ of home applicants were flagged as contextual students, of which the contextual flag was used on 20 to invite them for interview. The end result was four students registering on the 4-year Pharmacy (MPharm.) degree programme that would not otherwise have been given the opportunity. Three of these students have now completed the four year course and have graduated with upper second class degrees whilst the fourth student withdrew after second year due to personal circumstances. Data from this pilot study has since been used to help launch our Foundation Year programme which openly targets students from educationally disadvantaged backgrounds.
\end{abstract}

Key terms: admissions, contextual, widening access, foundation year.

\section{Introduction}

There is far more to undergraduate admissions than simply academic attainment. Indeed, the admissions process can be described as a 'delicate balance', where academic achievement should be viewed holistically in the context of an applicant's background. Factors such as socio-economic background, living in a deprived neighbourhood, personal factors such as having been in local authority care and the type of school attended have a significant impact on secondary school subject choices, attainment and ultimately aspirations to higher education. In this respect, there is a growing interest in the use of contextual data by universities and colleges; that is, data that puts academic attainment in the context of circumstances in which it has been obtained.

The use of contextual data by universities and colleges in the UK is not new. Most higher education institutions (HEIs) have for many years used data that is self-declared by the applicant and / or referee in their university application, and some may also use interviews, admissions tests, assessment of skills and other relevant information. However, there has not been a shared understanding across the sector of the purpose of contextual data or the methodologies used and the value it adds. Used appropriately (i.e not necessarily lowering entry grades), contextual data can mitigate such socio- 
economic factors by identifying those applicants that merit a place by using a wider range of indicators than attainment alone (Bridger, Shaw and Moore, 2012).

\section{Contextual Data}

To date, the use of contextual data can be seen most frequently in more selective HEIs where it is supported by an institution-specific rationale and is evidence based. As such, for HEI's to progress contextual admissions more effectively, robust contextual data is required that is consistent, reliable and accessible. An added advantage for using contextual data is that it is more measurable in terms of success outcomes and uptake than many other widening access schemes and can be also be assessed over a relatively short period. And such policies by universities are not only pursued through a commitment to equity: data would suggest that students from independent schools actually perform less well than state-school pupils, all other things being equal (HEFCE, 2003). Contextual data can therefore help improve the quality of HEIs in terms of final degree outcomes. If universities want to admit the best students, they should be competing for the top students from minorities and disadvantaged backgrounds, even if this does result in differential grade offers being made for the same subject. This article describes the experiences of the School of Pharmacy and Pharmaceutical Sciences at the University of Manchester in using contextual data to help select students with potential from groups that are usually under-represented in HE.

\section{Contextual Data Pilot Study}

Historically, the majority of entrants to the four-year Pharmacy (MPharm.) course at Manchester were selected almost entirely on the basis of A-level (or equivalent) results. However, in 2007, the School of Pharmacy participated in a pilot study run by University of Manchester central admissions looking at the use of contextual data to widen access to HE. The overall aim of the pilot study was to use information about applicants' educational and social background in undergraduate admissions processes. In an increasingly diverse applicant pool, it cannot be assumed that the ability and potential of all applicants is expressed accurately solely by their educational attainment. Students who have experienced educational or social disadvantage may not have had the same opportunities to develop their academic potential and this may have compromised their academic achievement. As described by Bridger, Shaw and Moore (2012), contextual data can be used to better understand attainment information. However, whilst it is not the task of HE admissions to compensate for educational or social disadvantage, it is a legitimate aim for universities to seek to recruit the best possible students regardless of background. 
Due to the availability and comparability of data, the use of contextual information was applied to UK Home applicants only. Key principles concerning the use of contextual data included the following:

- that each applicant would be considered on their own merits;

- that decisions would be evidence-based, verifiable and reliable and relevant to the admission-decision making process;

- that such mechanisms would only be used to complement and enhance existing selective mechanisms; and

- that what, how and when information is used will be transparent to applicants.

The contextual indicators that were used in the study are summarised in Table 1.

Table 1: Contextual Data Indicators used to Flag Applicants

\begin{tabular}{|l|l|}
\hline & $\begin{array}{l}\text { Description of Contextual Data Indicators } \\
\text { used to Generate Flags }\end{array}$ \\
\hline Indicator 1 & $\begin{array}{l}\text { Average School / College performance at } \\
\text { level 3 (A-level or equivalent). }\end{array}$ \\
\hline Indicator 2 & $\begin{array}{l}\text { Area-based indicator of disadvantage and } \\
\text { low progression to HE (using the Indices of } \\
\text { Multiple Deprivation). }\end{array}$ \\
\hline Indicator 3 & $\begin{array}{l}\text { Whether the applicant's parents have } \\
\text { experienced HE. }\end{array}$ \\
\hline Indicator 4 & $\begin{array}{l}\text { Whether an applicant has experienced a } \\
\text { period of local authority care prior to } \\
\text { application. }\end{array}$ \\
\hline
\end{tabular}

Where contextual data was being applied, a system of flagging or coding was undertaken, which could then be used at various stages in the admission-decision making process. To be flagged, applicants needed to qualify in at least two indicators, one of which had to be either the IMD or the school/college exam score. The only stand-alone criterion used in the pilot was whether an applicant identified themselves as having experienced a period of local authority care on their UCAS form. At the outset of the study it was agreed that each of the participating Faculties would use the contextual flag in the way that best suited their admission process. No applicant would be selected purely because their application was flagged. Rather, the flag would be used alongside all the information used by the Faculty to make admissions decisions. For Pharmacy, flags were used at the stage of selecting for interviews and review of applicants narrowly missing offer grades at confirmation (Figure 1). 
Figure 1: Use of Contextual Flags for Pharmacy Admissions

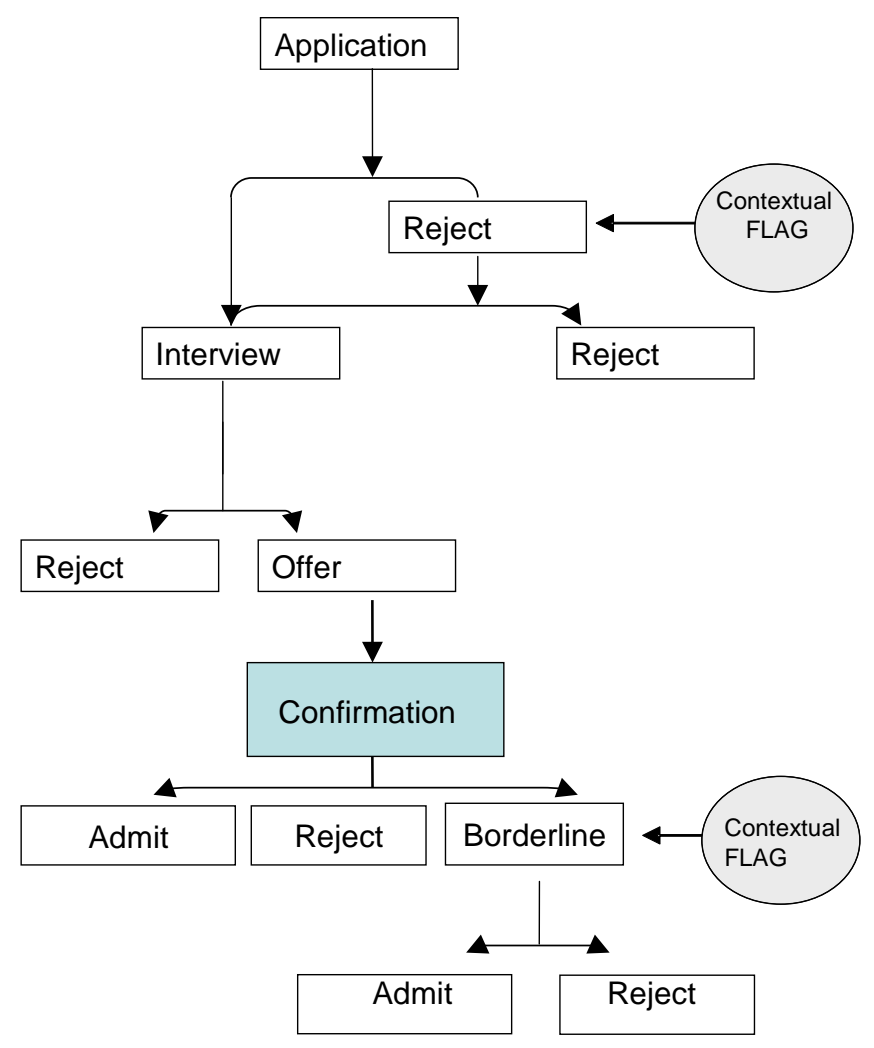

\section{School of Pharmacy Contextual Data}

Analysis of the UK Home admissions data for the School of Pharmacy revealed that of the 1,261 applications received, 341 (27\%) were flagged as satisfying the contextual requirements. Of those, 229 were invited for interview, of which the contextual data was used positively on 20. Hence, 20 applicants were invited for interview that would otherwise have been rejected. The 20 that were subsequently invited for interview were selected on the basis of perceived potential, in most cases obtained from the referee's statement. Applicants not invited for interview were rejected for a number of reasons including A-level subjects other than those required for Pharmacy, prioritising a different subject for study, or very poor predicted A-level grades. Following interview, 13 offers were made at standard entry grade level. Seven of the students declined our offer whilst five put Manchester as their firm choice and one as insurance. At results confirmation, three of the five students met the conditions of their offer, one missed it by a large margin and was rejected and one narrowly missed out on an automatic place on the course. The contextual information for this 
candidate was reviewed and the decision made to allow them onto the course with grades slightly below the normal acceptance level on the basis that they had significantly out-performed their school/college average score for 3 A-levels. Thus, for the 2007/2008 recruitment cycle, four students were admitted to the MPharm course at the University of Manchester through consideration of contextual information that in previous years, would have been rejected.

Three of these students successfully completed the full MPharm programme and graduated in July 2012. All three students gained upper second class degrees, including the student that had contextual considerations at both flags, with one student very narrowly missing out on a First class degree. The student that exited the course did so after their second year due to personal circumstances. Without taking into account their contextual data, these students would not have been able to study pharmacy.

\section{Contextual Data Usage Today}

Although this case study is based on a small applicant cohort, it does clearly demonstrate the positive benefits of using contextual data and how consideration of a range of social and demographic information can make a difference to the lives of some individuals. It is important to reiterate that the generation of a flag when processing an application does not necessarily lead to the lowering of our standard entry threshold offer. Admissions decisions have to be based on student's achievements and potential. Flagged applicants are simply being highlighted for 'further consideration' by admissions staff. In recognition of the positive benefits not only to Pharmacy, but also the other Academic Schools that participated in the pilot study, from September 2011 the University of Manchester has now rolled out contextual consideration (criteria modified to now also include consideration of Average School Performance at Level 2 [GCSE or equivalent] but not parental education) as a means of identifying exceptional students irrespective of background as a standard procedure for all courses.

In addition, the positive benefits of taking contextual information into consideration have led Manchester to develop a unique Pharmacy Foundation Year programme. This one year course, launched in 2009, openly targets applicants who have experienced educational and other disadvantage measured geo-demographically and by prior educational context. Following interview, students that satisfy the contextual requirements are made an offer that exceeds the average A-level score for their school / college, achievement of which will partially demonstrate their academic potential. To date, students that have progressed from this programme onto the four-year MPharm are achieving high marks and almost without exception are in the top $20 \%$ of their respective year groups. 


\section{Concluding Remarks}

The rationale for the implementation of using contextual data in admissions generally aligns with an HEI's aim to widen access to higher education and to achieve and maintain excellence. Applied robustly and within a holistic process, the use of contextual data in admissions can be an effective tool in identifying applicants with greatest potential to succeed in HE. Moreover, applied in a competitive environment, contextual data provides a means of ensuring that all applicants are considered equally, regardless of background factors over which they have no control. Whilst the number of contextual cases reported in this study did not make a significant impact on overall admissions numbers, they did make a huge and significant difference to the individuals concerned.

\section{References}

Bridger, K., Shaw, J \& Moore, J. (2012). Fair Admissions to Higher Education, SPA

Report: http://www.spa.ac.uk/documents/Full_SPA_Contextual_data_Researc h_Report-Feb2012.pdf.

Higher Education Funding Council for England (HEFCE) (2003). Schooling Effects on Higher Education Achievement, Bristol: HEFCE 